\title{
REVIEW
}

\section{Biology-driven cancer drug development: back to the future}

\author{
Christopher J Lord* and Alan Ashworth*
}

\begin{abstract}
Most of the significant recent advances in cancer treatment have been based on the great strides that have been made in our understanding of the underlying biology of the disease. Nevertheless, the exploitation of biological insight in the oncology clinic has been haphazard and we believe that this needs to be enhanced and optimized if patients are to receive maximum benefit. Here, we discuss how research has driven cancer drug development in the past and describe how recent advances in biology, technology, our conceptual understanding of cell networks and removal of some roadblocks may facilitate therapeutic advances in the (hopefully) near future.
\end{abstract}

\section{The good news and the bad news}

In the past 100 years our grasp of the biology of cancer has come a very long way. We now have a working knowledge of how tumors initially form, grow and spread. Importantly, vast amounts of information about features distinguishing tumor from normal cells is being accumulated, resulting in frequent, major new insights into cancer biology.

The bad news is that translating this information into the development of new treatments, or even refining the use of the ones we already have, has been much less impressive. Clinicians will attest that cytotoxic chemotherapy regimens, developed with the limited biological information available at the time of their development, remain the mainstay of treatment for most cancers. There are a few high-profile examples of rationally and molecularly targeted therapies, but we need to do much better if we are to shift the entire pattern of treatment to drugs that have high potency but mild side effects.

*Correspondence: chris.lord@icr.ac.uk, alana@icr.ac.uk

The Breakthrough Breast Cancer Research Centre, The Institute of Cancer Research, Fulham Road, London, SW3 6JB, UK

\section{A brief history of old-school and new age drug discovery}

Several articles have extensively reviewed the history of cancer drug development [1] and so here we will only pick out the salient points. It is widely accepted, although clouded by the secrecy of war [2], that the first tentative steps to treating cancer with drugs emanated from the observation that exposure to chemical warfare agents ('poison gases'), such as nitrogen mustards, could limit the proliferative nature of rapidly dividing lymphoid cells. Goodman and Gilman reasoned that this could translate into a therapeutic context and used the nitrogen mustard mustine to treat a patient with non-Hodgkin's lymphoma [3]. Around the same time, and building on the observation that the vitamin folic acid could stimulate acute lymphoblastic leukemia (ALL) cells, Farber used folate analogs such as aminopterin and then amethopterin (methotrexate) to treat ALL, in what is often heralded as the first 'rational' drug development approach [4]. Burchenal, Hitchings and Elion used a similar approach to assess the potential of purine analogs, identifying 6-mercaptopurine (reviewed in [5]). The nitrogen mustards and folate and purine analogs were much later shown to interfere with DNA replication, in part explaining their anti-tumor activity. In contrast, the alkaloids of the Madagascar periwinkle, such as vincristine, originally identified in the 1950s in a screen for anti-diabetic drugs, block tumor cell division, and therefore proliferation, largely by inhibiting microtubule polymerization [6]. All these therapies remain in clinical use today.

Following the discovery of chemotherapeutics, the next significant advance came in the 1960s with the straightforward notion of combining drugs. The rationale for this came from the treatment of tuberculosis, for which antibiotics, each with a different mechanism of action, were more effective when used in combination. For cancer, it was considered that the development of resistance to a battery of agents used concurrently, rather than a single drug, was less likely. Using this approach, Holland, Freireich and Frei pioneered a combination of methotrexate and 6-mercaptopurine for treating children with ALL (reviewed in [7]). Today, most cancer chemotherapy regimens use this same paradigm. 
Anti-hormone therapy has been spectacularly successful in the treatment of breast cancer. Tamoxifen, the most successful of these agents, was identified in the early 1960 s as an estrogen receptor (ER) antagonist (more correctly, a selective estrogen receptor modulator). This drug, originally developed by Walpole's group at ICI as a potential contraceptive, showed its potential when initially trialed for breast cancer in 1971 [8]. Subsequent clinical trials have confirmed the utility of this drug in $\mathrm{ER} \alpha$-positive breast cancer patients and tamoxifen has now been given to millions of women and has saved countless lives.

The impact of biology on cancer drug development at this stage was limited; most therapies had been identified either by serendipity or had been selected primarily on the basis that they could limit cell division. However, in the 1970s and 1980s, the advent of gene manipulation and molecular genetic analysis changed the nature of biological research forever and with it the drug discovery and development process. Molecularly targeted therapies could now be contemplated, that is, drugs that were rationally designed or selected to inhibit the activity of specific molecules (Table 1). If used in the right patient population - on tumors with specific molecular lesions these therapies promised significant tumor selectivity. One of the most remarkable examples of the development of such a targeted therapy, to which biological research made a critical contribution, is that of imatinib (Gleevec; Figures 1 and 2).

Chronic myelogenous (or myeloid) leukemia (CML) was first identified in 1845 by Bennett and Virchow [9] and has been treated with a wide range of drugs [10]. In 1960, Nowell and Hungerford described a consistent chromosomal abnormality - the 'Philadelphia Chromosome', named for the city in which they worked - in patients with CML [11]. This was later shown by Rowley to be formed from a reciprocal translocation of DNA between the long arms of chromosomes 9 and 22 [12] (Figure 1a).

In the 1970s and 1980s several oncogenes present in cancer-causing viruses were shown to have normal cellular equivalents that became altered in human cancers. For example, the Abelson murine leukemia retrovirus (A-MuLV) [13] was shown to carry a transforming gene $(v A B L)$ that had a normal cellular homolog, $\mathrm{c} A B L$ [14]. Subsequently, the $c A B L$ gene was shown to be involved in the chromosomal rearrangement in $\mathrm{CML}$, translocating from chromosome 9 to the breakpoint cluster region $(B C R)$ gene on chromosome $22[15,16]$ (Figure 1a). This results in the production of a fusion gene between $B C R$ and $c A B L$ [17]. In 1981, $v A B L$ had been identified as a protein kinase [18] and the $B C R-A B L$ fusion mRNA was later shown to encode a constitutively active kinase whose activity could transform cells both in vitro [19] and in vivo [20,21]. Therefore, it was recognized that targeting the catalytic activity of ABL could potentially deliver a therapeutic window between tumor cells with constitutive activity of BCR-ABL and normal cells with more tightly controlled ABL activity. Subsequent studies on BCR-ABL biology have focused on defining the links between BCR-ABL activity and the pathological characteristics of CML and other diseases [22].

At the same time as the transforming activity of $B C R$ $A B L$ had been established, several observations were made that, while not critical to understanding the biology of BCR-ABL and CML, were absolutely crucial to the eventual development of drugs used to treat the disease. First, it was recognized that certain small molecules could inhibit the activity of protein kinases [23]. Second, methods for expressing large amounts of active human proteins in insect cells were refined, allowing $\mathrm{BCR}-\mathrm{ABL}$ protein to be generated to enable a drug development program [24]. Finally, antibody production technology had progressed to such a point that the activity of protein kinases could be monitored in a relatively robust manner. All of these factors enabled a team led by Matter at CibaGeigy to initiate a kinase small molecule inhibitor development program. By 1996, STI517 (imatinib) had been identified and its activity confirmed in BCR-ABL cells by Druker and colleagues [25]. In 1998, phase I clinical trials commenced [26], leading to drug approval by the US Food and Drug Administration in 2001.

At this time, the first resistance mechanisms to imatinib were identified [27]. These could have been due to mechanisms previously noted for chemotherapy resistance, such as enhanced metabolism or efflux of the drug from cells. However, in what turned out to be a general phenomenon, Sawyers and colleagues [27] identified BCR-ABL mutations in patients who had relapsed on imatinib treatment, which rendered the enzyme resistant to the inhibitory effects of imatinib [28]. The use of a three-dimensional structure of the catalytic domain of $\mathrm{ABL}$ in a complex with an imatinib variant [29] also gave insight into this phenomenon and has furthered our understanding of the mode of action of imatinib and the second-generation ABL inhibitors such as nilotinib [30] and dasatinib [31]. These latter drugs can overcome resistance caused by some, but importantly not all, BCRABL mutations. Very recently, allosteric inhibitors of ABL have been identified [32] (allosteric being shorthand for 'binding outside the catalytic site'). These latter molecules bind the myristate binding site of ABL, as opposed to the ATP binding site targeted by imatinib and related inhibitors. This inhibitor-target interaction does however, induce a structural change in the catalytic domain of the kinase and this in turn inhibits the enzyme activity of ABL. When combined with imatinib, an ABL allosteric inhibitor can overcome resistance caused by 
Table 1. Some examples of targeted therapies for cancer

\begin{tabular}{|c|c|c|c|}
\hline Drug & Brand name & Drug target* & Cancer types \\
\hline \multicolumn{4}{|l|}{ In clinical use } \\
\hline Bevacizumab & Avastin & VEGF & Colorectal, non-small cell lung, breast, renal \\
\hline Bortezomib & Velcade & Proteasome & Myeloma, lymphoma \\
\hline Celecoxib & Onsenal & $\operatorname{cox} 2$ & Familial adenomatous polyposis \\
\hline Erlotinib & Tarceva & \multirow{4}{*}{ EGFR } & \multirow{4}{*}{ Non-small cell, lung, colorectal, head and neck } \\
\hline Gefitinib & Iressa & & \\
\hline Cetuximab & Erbitux & & \\
\hline Panitumumab & Vectibix & & \\
\hline Imatinib & Gleevec & \multirow{3}{*}{ BCR-ABL, CKIT, PDGFR } & \multirow{3}{*}{ Leukemia, gastrointestinal } \\
\hline Dasatinib & Sprycel & & \\
\hline Nilotinib & Tasigna & & \\
\hline Methotrexate & & DHFR & Multiple cancer types \\
\hline RAD001 & Certican & \multirow{2}{*}{ mTOR } & \multirow{2}{*}{ Renal } \\
\hline Temirolimus & Toricel & & \\
\hline Sorafenib & Nexavar & \multirow{2}{*}{ VEGFR, RAF, CKIT, PDGFR } & \multirow{2}{*}{ Renal, hepatic } \\
\hline Sunitinib & Sutent & & \\
\hline Topotecan & Hycamtin & \multirow{2}{*}{ Topoisomerase I } & \multirow{2}{*}{ Multiple cancer types } \\
\hline Irinotecan & Camptosar & & \\
\hline Trastuzumab & Herceptin & ERBB2 & Breast \\
\hline Lapatinib & Tykerb & HER2, EGFR & Breast \\
\hline Tamoxifen & Nolvadex & ERa & Breast \\
\hline Exemestane & Aromasin & \multirow{3}{*}{ Aromatase cytochrome P450 } & \multirow{3}{*}{ Breast } \\
\hline Anastrozole & Arimidex & & \\
\hline Letrozole & Femara & & \\
\hline Rituximab & MabThera & \multirow{2}{*}{ CD20 } & \multirow{2}{*}{ Lymphoma } \\
\hline Tositumomab & Bexxar & & \\
\hline \multicolumn{4}{|l|}{ In development } \\
\hline $17 A A G$ & & \multicolumn{2}{|l|}{ HSP90 } \\
\hline ABT-737, ABT-263, Obatoclax & & \multicolumn{2}{|l|}{$B C L-X L, B C L-2$} \\
\hline Alvocidib & & \multicolumn{2}{|l|}{ CDKs } \\
\hline Olaparib, AG014699 & & \multicolumn{2}{|l|}{ PARP1/2 } \\
\hline BEZ235 & & \multicolumn{2}{|l|}{$\mathrm{PI} 3 \mathrm{~K}$} \\
\hline GRN163L & & \multicolumn{2}{|l|}{ hTERT } \\
\hline Mapatumumab & & \multicolumn{2}{|l|}{ TRAIL Receptor } \\
\hline Nutlin-3 & & \multicolumn{2}{|l|}{ MDM2 } \\
\hline PLX4032 & & \multicolumn{2}{|l|}{ BRAF } \\
\hline GDC-0449 & & \multicolumn{2}{|l|}{$\mathrm{SMO}$} \\
\hline PF-0477736 & & \multicolumn{2}{|l|}{ CHK1 } \\
\hline
\end{tabular}

*Target abbreviations: $\mathrm{BCL}-2$, anti-apoptotic protein $\mathrm{BCL}-2 ; \mathrm{BCL}-\mathrm{XL}$, anti-apoptotic protein $\mathrm{BCL}$ extra large; $\mathrm{BCR}-\mathrm{ABL}$, fusion protein of breakpoint cluster region and tyrosine kinase ABL1; BRAF, protein tyrosine kinase BRAF; CD20, B-cell phosphoprotein CD20; CDKs, cyclin-dependent kinases; CHK1, serine/threonine kinase CHK1; CKIT, tyrosine kinase c-KIT; COX2, cyclooxygenase 2; DHFR, dihydrofolate reductase; EGFR, epidermal growth factor receptor; ERa, estrogen receptor a; HER2, human epidermal growth factor receptor 2; HSP90, heat shock protein 90; hTERT, telomerase reverse transcriptase; MDM2, murine double minute 2; mTOR, mammalian target of rapamycin; PARP1/2, poly(ADP-ribose) polymerase 1/2; PDGFR, platelet-derived growth factor receptor; PI3K, phosphatidylinositol 3-kinase; RAF, small GTPase RAF; SMO, Smoothened; TRAIL receptor, TNF-related apoptosis-inducing ligand receptor; VEGF, vascular endothelial growth factor; VEGFR, VEGF receptor.

BCR-ABL mutations such as T315I [32], illustrating the potential benefit of combining different modes of inhibition on the same target.

As a final note in the imatinib story, biological insight has been used to expand the range of patients that might be treated by this drug. As well as ABL, imatinib also inhibits related kinases, such as the cytokine receptor cKIT and platelet-derived growth factor receptors
(PDGFRs). Constitutively active cKIT mutations are found in gastrointestinal stromal tumors and translocations in the PDGFRB gene are found in diseases such as chronic myelomonocytic leukemia (CMML). Imatinib has already shown considerable success for the treatment of gastrointestinal stromal tumors [33] and preliminary results suggest that it could also work in CMML characterized by PDGFRB alterations [34]. 


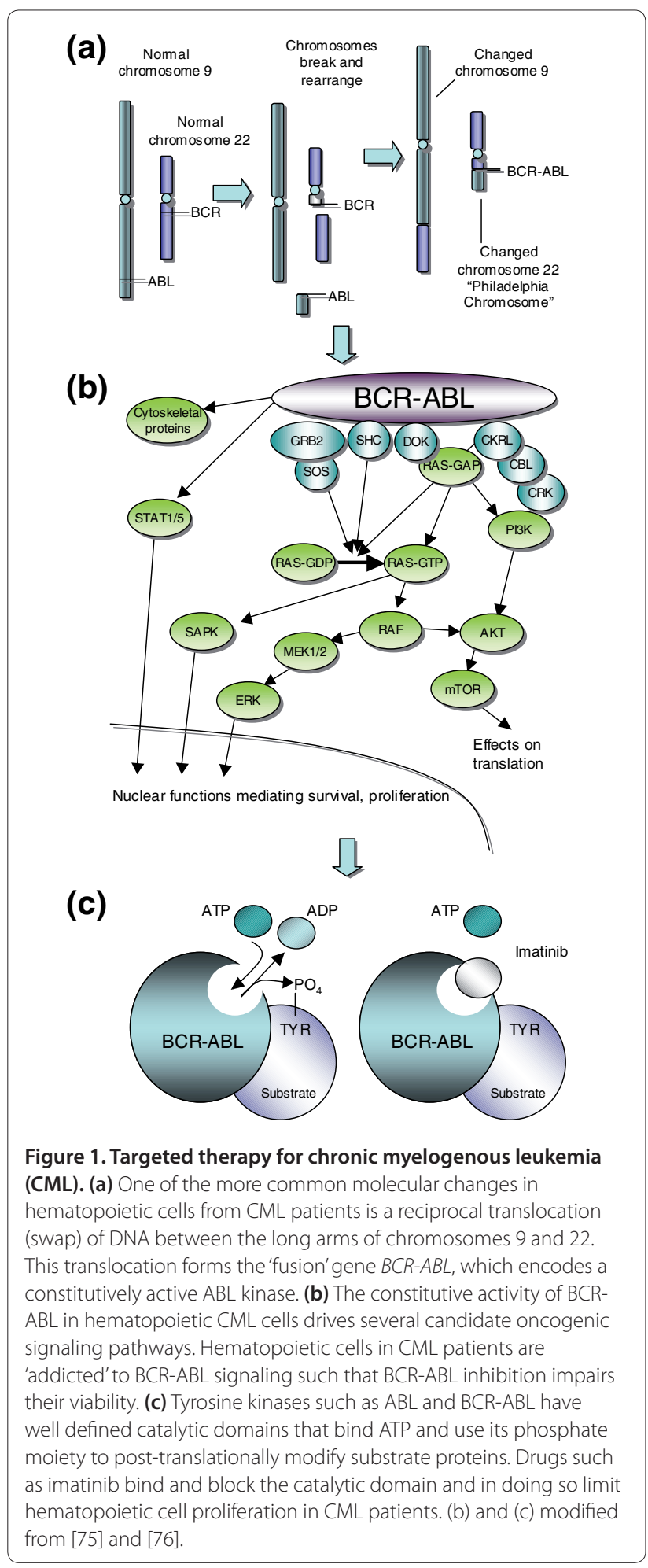

Similar successful approaches have resulted in the targeting of other oncogenes, such as epidermal growth factor receptor (EGFR; targeted by gefitinib and erlotinib, whose brand names are Iressa and Tarceva, respectively [35]) and Human epidermal growth factor receptor 2

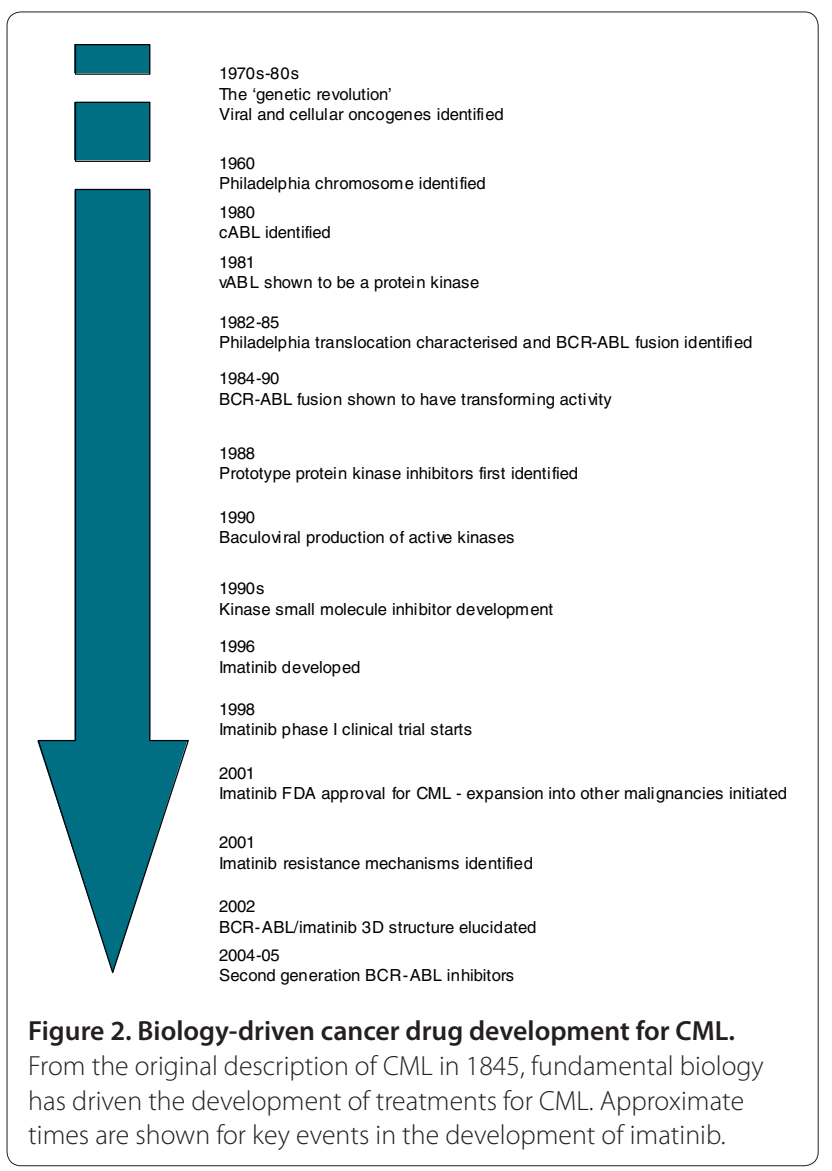

(HER2; targeted by trastuzumab/Herceptin [36]). More recently, the targeting of oncogenic Hedgehog signaling in medulloblastoma and basal cell carcinoma $[37,38]$ has also shown considerable promise (Figure 3). Hedgehog (hh) was originally discovered by Nüsslein-Volhard and Wieschaus nearly 30 years ago as a 'segment polarity' gene that controls Drosophila embryonic cuticle patterning [39]. Vertebrate orthologs of $h h$ were identified in the early 1990s and subsequent studies have not only dissected the mechanisms underlying hedgehog signaling but have also shown Hedgehog to be involved in various aspects of animal development, from cell fate through to body length [40]. Importantly, Hedgehog signaling has been shown to be dysregulated in human cancers, notably gastrointestinal tumors, prostate cancer, hematological malignancies and gliomas. Recent clinical studies suggest that medulloblastomas and basal cell carcinomas that rely on Hedgehog signaling can be treated with a small molecule inhibitor that targets the $h h$ signaling mediator, Smoothened [37,38].

Another notable advance in targeted therapy development has been in the development of small-molecule inhibitors of the oncogenic protein BRAF [41,42]. The $B R A F$ gene, a viral oncogene homolog that encodes a 

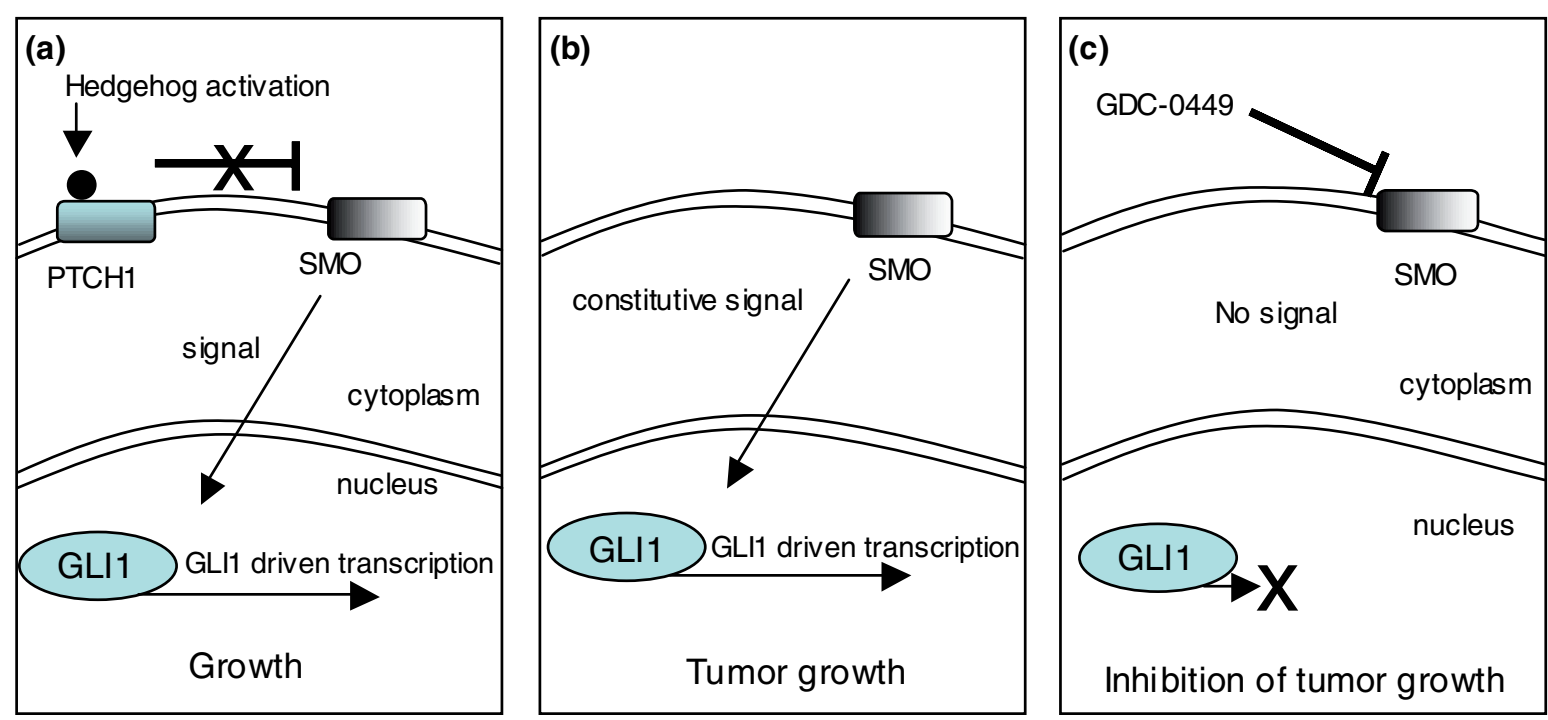

Figure 3. Targeting oncogenic Hedgehog signaling. (a) In normal cells the Patched homolog, PTCH1, blocks the activation of the Smoothened homolog, SMO. Binding of Hedgehog ligand to PTCH1 removes the repression of SMO, and this drives transcriptional changes via the activity of GLI proteins. (b) In tumors such as basal-cell carcinoma and medulloblastoma, mutations in PTCH1 or SMO lead to constitutive, ligand-independent signaling and an addiction to hedgehog signaling. (c) Blocking the activity of SMO with a small molecule, GDC-0449 can ablate hedgehog signaling and thus inhibit cell growth in addicted tumor cells.

kinase involved in the RAS/RAF/MEK/ERK pathway (Figure $1 \mathrm{~b}$ ), is mutated in up to $70 \%$ of melanomas, with mutations such as BRAF V600E causing constitutive MEK/ERK activation. This MEK/ERK activation drives tumour cell proliferation and survival. Although there are various approaches designed to target RAS/RAF/MEK/ ERK signaling [41], much effort has been placed in designing small-molecule BRAF inhibitors [42]. Clinical studies now suggest that targeting constitutively active BRAF in patients with melanomas or colorectal tumors characterized by V600E mutations can have significant clinical benefit [43] and, very recently, a detailed study of BRAF/RAS/CRAF signaling interactions has provided further insight into, and potential refinement of, this approach [44].

Of course, although targeted therapies are heralded as a considerable advance from standard chemotherapies, they are still affected by resistance and toxicity effects. Returning to imatinib, $B C R-A B L$ mutations can drive resistance $[27,28]$, and moderate side effects of imatinib treatment, such as edema, do occur. However, with other targeted agents, such as sunitinib, toxicities such as a hand and foot skin reaction can be more severe and in fact dose-limiting. Some of these toxicities are likely to be caused by inhibition of the desired therapeutic target in normal tissues, whereas others may be due to the multikinase inhibition profile of some of the drugs used clinically. Nevertheless, targeted agents are generally well tolerated compared with chemotherapies and tend to deliver larger therapeutic windows.

In summary, in contrast to more traditional cancer therapies, the development, clinical use and refinement of imatinib and other targeted therapies could not have occurred without the considerable groundwork of biologists from many different disciplines. Nevertheless, putting this together required the vision and application of individuals willing to apply these developments.

\section{The future of cancer research?}

We do need to recognize and applaud the progress that has been made in biologically targeted therapeutic development. This is a great validation of the role of biological insight, but how this field might develop in the future is less clear. To frame this discussion, it is worth noting some of the key problems currently faced in cancer therapy.

First, there are some effective drugs but they are not used in an optimal manner. For some cancer types, there are a series of drugs that work relatively well but the response to them is very heterogeneous. We need to understand the reasons for this heterogeneity and tailor the right treatment to the individual patient, rather than finding the best for the average patient. Second, more often than not, even after an initial response, patients frequently relapse - we need a clearer understanding of the mechanisms underlying relapse and drug resistance if we are to overcome them. Third, for some cancer types, 
there are no really effective therapies and we need to identify new drug targets and develop methods of exploiting them. And finally, with the exception of a minority of cancers, preventative strategies are not available.

A fair assessment of the situation would be that we are a considerable way off from solving these problems. Understanding more about the biology of cancer will be key if we are to make significant advances. But we do need to go a step further; biologists need to be continually alert to the possibility of translating their findings into changing clinical practice. Several recent conceptual and experimental advances might help achieve this but, in short, all cancer biologists need to become, in part, 'translational'.

\section{A deeper understanding of the altered universe of the cancer cell}

Understanding normal cell behavior has been a significant goal of modern biology and of course this is extremely important in defining the neoplastic process. However, it is now widely recognized that this is not enough in itself as there are a constellation of changes in the altered and forever adapting universe of the cancer cell. Hanahan and Weinberg [45] summarized an immense body of work by listing the 'hallmarks' of cancer cells and tumors - a limitless replicative potential, resistance to apoptosis, insensitivity to anti-growth signals, selfsufficiency in growth signals, tissue invasion and metastasis, and sustained angiogenesis. Building on this model and our deeper understanding of cancer biology, Luo, Solimini and Elledge [46] have proposed additional characteristics, such as: evading immune surveillance [47]; an elevated DNA damage/replication response caused by elevated replication rates and also DNA repair defects in tumor cells [48]; proteotoxic stress - an increase in the amount of toxic, unfolded proteins in tumor cells and the resultant heat shock protein response [49]; mitotic stress/chromosomal instability [50]; metabolic stress - the increased use of glycolysis rather than oxidative phosphorylation as a means of producing ATP [51]; and oxidative stress - an increase in the level of reactive oxygen species in tumor cells [52].

The obvious translational output of defining these characteristics is in identifying additional means by which tumor cells can be targeted. For example, the renewed interest in cancer cell metabolomics and metabolic stress [53] will most likely lead to therapies that target tumor-specific reliances on particular aspects of glucose metabolism. Furthermore, the classification of these characteristics presents significant new opportunities for reinvention of the combination therapy paradigm for cancer therapy. Combinatorial targeting of different 'hallmarks' of cancer with targeted therapies (Figure 4) could elicit an enhanced and durable therapeutic response, as is seen with combinations of classical chemotherapies.

\section{Embracing the complexity of the cancer cell}

The control of cell growth and behavior has long been recognized to be complex. However, we are increasingly daunted by exactly how great a challenge it will be to understand or predict normal cell behavior or the rewiring that goes on in cancer cells. There are some recent examples in which the discovery of entire levels of cellular regulation, such as microRNAs, add yet another layer of complexity.

Moreover, our restricted and naive view of biology has meant that, in general, understanding cell behavior has been by studying discrete pathways. These pathways are often a misleading oversimplification of the complex molecular networks that control cell behaviour. However, help may be at hand in addressing this complexity in 'systems' approaches. Although still in their infancy, these computational approaches coupled with deep transcriptomic, genomic proteomic or metabolic profiling promise an integrated approach and, with this, a better understanding of interacting molecular networks. This should allow us to start thinking seriously about how drugs perturb networks rather than discrete pathways and use this information to develop new 'network' therapeutic strategies.

A significant challenge in cancer drug development, 'drugging the undruggable', is being addressed by exploiting molecular networks. An example has been the use of poly(ADP-ribose) polymerase (PARP) inhibitors to treat BRCA-deficient cancers. BRCA1 and BRCA2 are both classical tumor suppressor genes: loss-of-function mutations disable BRCA1 and BRCA2 proteins and strongly predispose to cancer. Targeting tumor suppressor genes presents a particular problem: unlike gain-offunction oncogenic events such as the $B C R-A B L$ fusion, it is not obvious how to pharmacologically target a tumor suppressor protein that is dysfunctional or even completely absent. However, exploiting knowledge of molecular networks may be of significant benefit here. In 2005, we demonstrated that tumor cells with deficiencies in either the $B R C A 1$ or $B R C A 2$ tumor suppressor genes are over 1,000 times more sensitive to potent inhibitors of the DNA repair protein PARP [54]. Underlying these observations is a network of synthetically lethal genes (Figure 5a).

Two genes or proteins are synthetically lethal when inactivation of either gene/protein is still compatible with cellular viability but inactivation of both leads to cell death [55]. Often, synthetic lethal relationships represent networks of proteins that show a form of functional buffering, and this seems to be the case with BRCA proteins and PARP. PARP is involved in the repair of 


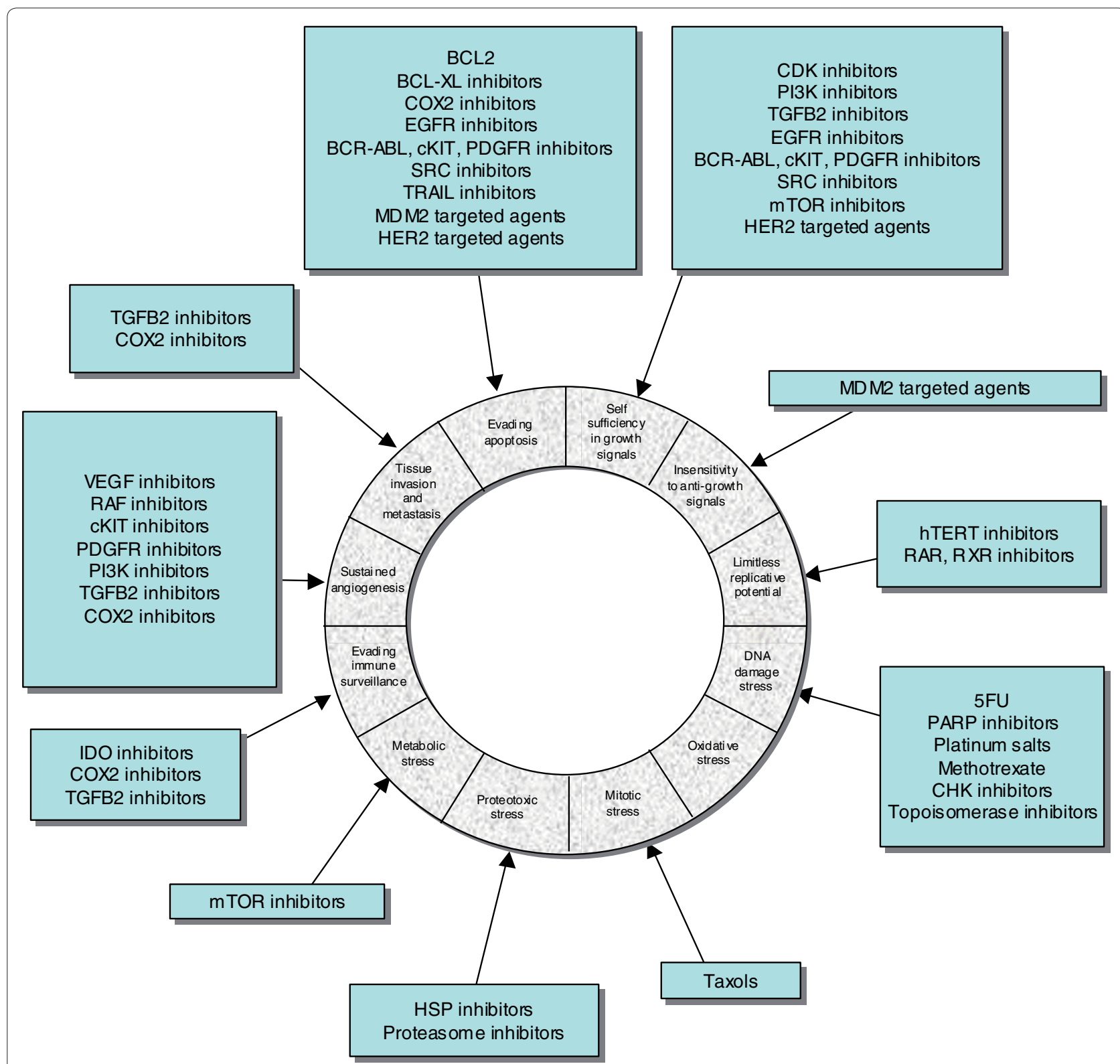

Figure 4. Hallmarks of cancer. The dissection of cancer biology has allowed the characteristics of tumor cells to be more accurately detailed. Drug classes targeting each of the characteristics are also shown (outside ring). Adapted from [46].

DNA breaks in a single strand of DNA. In normal cells, PARP inhibition and the resultant increase in DNA single strand breaks is functionally compensated for by a second form of DNA repair, homologous recombination. Homologous recombination is controlled by BRCA1 and BRCA2 - when BRCA proteins are defective, as is the case in tumors from breast, ovarian and prostate cancer patients carrying germline $B R C A$ gene mutations, this functional buffering is lost, and cells become exquisitely sensitive to PARP inhibitors (Figure 5b,c). These original in vitro observations have been translated into clinical trials and early results suggest significant tumor responses accompanied by relatively mild side effects when compared with standard chemotherapies [56]. This suggests that the large therapeutic window observed in the laboratory may indeed translate into the clinic. Although expanded clinical trials are needed to prove that such synthetic lethal approaches really do deliver larger therapeutic windows, the preliminary indications are that exploiting molecular networks may be a viable approach.

As discussed above, a large amount of effort has also been invested in targeting oncogenes as therapeutic targets. It is thought that tumor cells can be 'addicted' to 
(a)

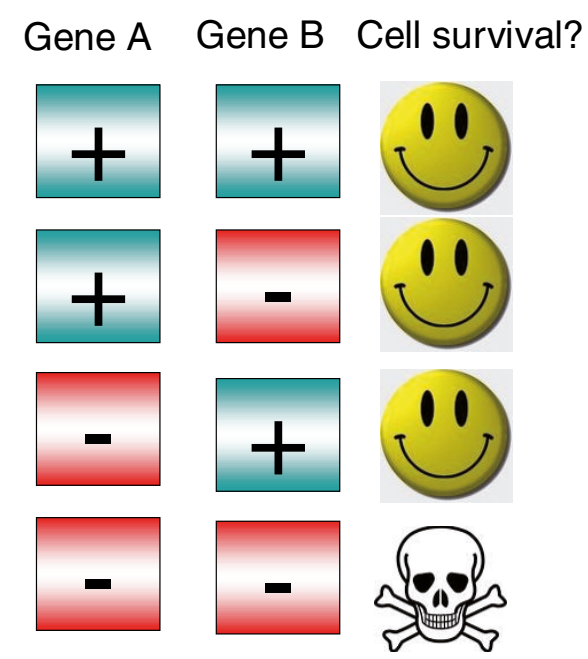

(c)

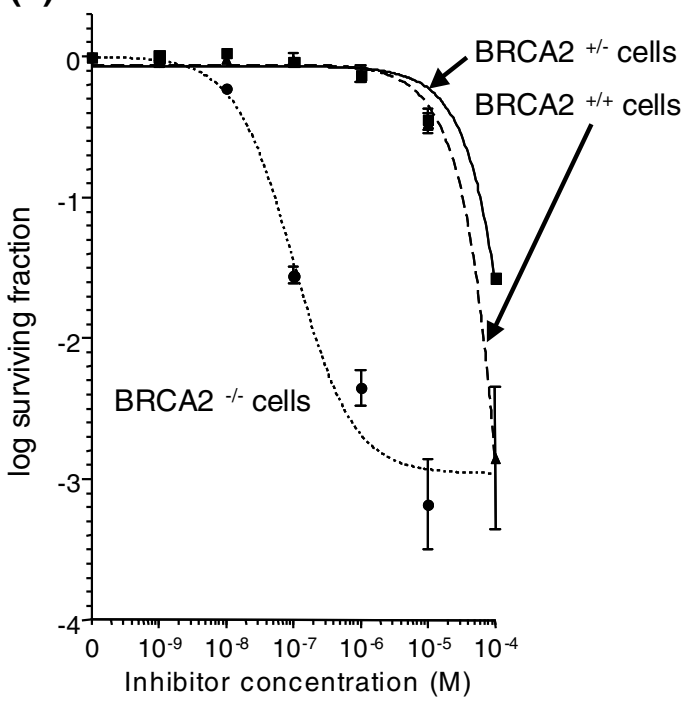

(b)
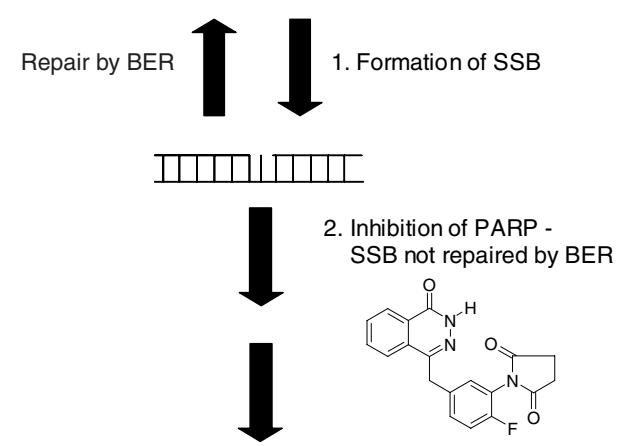

3. S phase: replication fork moves toward persistent SSB
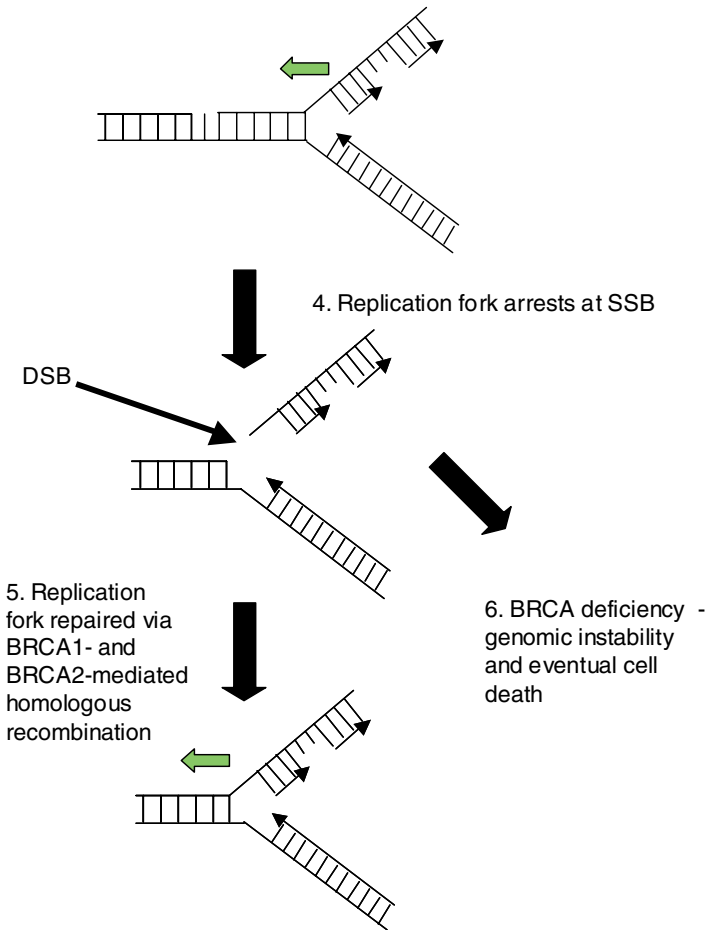

Figure 5. A synthetic lethal network exploited in cancer treatment. (a) Two genes or proteins are synthetically lethal when inactivation of either gene/protein is still compatible with cellular viability but inactivation of both leads to cell death [55]. Often synthetic lethal relationships represent networks of proteins that show a form of functional buffering. (b) A model for synthetic lethality using PARP inhibitors [54]. DNA is constantly damaged, both by environmental and by normal physiological processes. One of the more common forms of DNA damage is the formation of DNA single strand breaks (SSBs; step 1). SSBs are normally rapidly repaired by a process known as base excision repair (BER). BER is instigated by the activity of the poly(ADP ribose) polymerase, PARP1, and when PARP1 is inhibited (an example PARP inhibitor is shown), SSBs persist (step 2). As cells enter S phase, and DNA is replicated; replication forks are eventually stalled by persistent SSBs (step 3; the direction of a replication fork is shown by the green arrow). If not rapidly repaired, stalled replication forks can often degenerate and form DNA double strand breaks (DSBs), which are highly likely to be lethal (step 4). In normal cells, an additional DNA repair process, homologous recombination (HR), can repair stalled replication forks and DSBs (step 5). HR is mediated by BRCA1 and BRCA2 and acts as a functional buffer to enable normal cells to survive the effects of PARP and BER inhibition. Conversely, in patients with germ-line BRCA gene mutations, tumor cells show a severe HR defect (step 6). PARP inhibition combined with HR deficiency leads to tumor cell death either driven by the formation of lethal DSBs or because mutagenic forms of repair predominate in the absence of HR. The genomic instability that follows the use of these non-HR forms of DSB repair eventually limits the fitness and viability of tumor cells. (c) Synthetic lethality in in vitro cell culture. Clonogenic assays, which estimate tumor cell survival, demonstrate that tumor cells with either BRCA1 or BRCA2 deficiency are profoundly sensitive to potent PARP inhibitors such as KU0058948 (Kudos/AstraZeneca). Reproduced, with permission, from [54]. In vitro synthetic lethality translates into clinical synthetic lethality [56]. Computed tomographic (CT) scans of the abdomen in a patient with advanced ovarian cancer and BRCA mutation family history showed a reduction in the size of a peritoneal tumor nodule by $66 \%$ over a 4-month treatment period during which she received a potent PARP1 inhibitor, olaparib, at a dose of 100 mg, twice daily, for 2 of every 3 weeks. CT scans of the abdomen in another patient with advanced ovarian cancer, who had a BRCA1 mutation (4693delAA), showed complete regression of a peritoneal tumor nodule over a 4-month treatment period with olaparib ( $200 \mathrm{mg}$, twice daily) for a year. 
the activity of an oncogene [57], such that once the oncogene activity (or the pathway it controls) is blocked, tumor cells can no longer survive. Therefore, if one can identify an activated oncogene that a tumor cell is addicted to, there is the possibility of therapeutic approach to inhibit it. However, a significant problem arises if the target is not particularly suited to pharmacological inhibition. For example, a significant number of tumors are driven by either $M Y C$ or RAS oncogenes, but as transcription factors and GTPases, respectively, these proteins have been difficult to target, compared with, for example, protein kinases such as BCR-ABL.

One solution is to exploit molecular networks; the activity of oncogenes such as $M Y C$ or RAS results in considerable adaptive rewiring of cellular networks and tumor cells may become 'addicted' to these changes. These 'non-oncogene addictions' [46] could be therapeutically targeted. By performing high-throughput loss-offunction genetic screens that exploit RNA interference technology [58], Gilliland and colleagues [59] showed that tumor cells with mutant $R A S$ have acquired a dependence on the kinase STK33; tumor cell molecular networks have been re-wired such that STK33 now becomes critical whereas it is not in normal cells. Studies by Elledge and colleagues [60] and Hahn and colleagues [61] have also identified additional addictive effects in tumor cells that depend on RAS activity and similar work has elicited targets for MYC-driven cancers [62]. Whether these effects can ultimately be exploited therapeutically remains to be seen, but these proof-of-principle experiments clearly highlight the potential for network targeting.

Akin to the approach of exploiting the complexity of cancer cells, the integration of multiple data types is also now proving a powerful tool to identify novel cancer drug targets. This is proving particularly true when functional genomic screens, such as those using RNA interference, are combined with molecular profiling techniques. For example, Hahn and colleagues recently screened a small panel of colorectal tumor cell lines with an RNA interference library to identify $C D K 8$, a gene that not only controlled tumor cell viability but also modulated WNT signaling, an oncogenic pathway commonly active in colorectal cancer [63]. By integrating these screen data with the genetic profiles of colorectal adenocarcinomas, they demonstrated that the CDK8 gene was also amplified in a significant proportion of colorectal tumors, suggesting that it could be a promising drug target. Furthermore, the $C D K 8$ gene copy alteration could also serve as a biomarker with which to select patients for treatment with a CDK8 targeting agent, once developed. Similar studies have also used the integration of a wide variety of disparate data types, such as gene expression profiles, immunohistochemical profiles, metabolic profiles and forms of functional analysis, to identify novel cancer drug targets $[64,65]$. With the availability of technology, such as next generation sequencing, that offers the rapid dissection of cancer genome and transcriptome sequences [66-70], these integrated approaches are likely to become commonplace.

These next generation profiling technologies may also allow us to further our understanding of intra- and intertumor heterogeneity. It is well established that tumors from patients with diseases that are similar in clinical presentation are often distinct at the molecular level (for example, in terms of the transcriptomic profile or genomic content). Furthermore, heterogeneity also exists between primary and metastatic lesions from the same patient and also within individual tumors. It is likely that this heterogeneity explains, in part at least, differing responses to therapy between ostensibly similar tumors. One approach to understanding this heterogeneity is to first catalog it, and much effort has already gone into the characterization of tumor heterogeneity at the genomic and transcriptomic levels, with a seminal example being the gene expression profiling of 65 breast tumors [71].

With the advent of next generation sequencing we are now seeing the first reports of base-pair resolution DNA sequences of human tumors $[68,69]$. This trickle will turn into a torrent as the cost of these profiling approaches falls, allowing us to properly address heterogeneity and to further tailor treatment to the individual. Nevertheless, the first few tumor genome DNA sequences are already informing our understanding of cancer biology and hinting at therapeutic approaches. For example, the partial DNA sequence of a range of breast tumors and tumor cell lines already suggests that particular DNA repair defects are present, as represented by the specific patterns of DNA deletion and rearrangement that are left behind as footprints in the tumor genome [69]. Similarly, the type and number of mutations found in the genome sequences of a melanoma cell line and a lung tumor cell line $[68,69]$ seem to reflect the environmental agents (exposure to ultraviolet light and tobacco use, respectively) that initially fostered tumorigenesis. Such base-pair resolution DNA sequences could be used as diagnostics to identify, for example, specific DNA repair defects and to select therapies accordingly. Similar advances in proteomic [72] and also metabolic [73] profiling could also address heterogeneity and inform therapeutic development. It is of course implicit that with this wealth of biological data, we need to make advances in our ability to process and analyze such large data collections.

\section{Biology-driven cancer drug development}

Returning to the here-and-now, there are several organizational and logistical roadblocks to the application of basic research in cancer therapeutic development that have made this avenue daunting to many biologists. The 
first is understanding and recognizing the actual clinical issues. This means that interactions with clinicians who understand the benefits of basic research need to be fostered and a meaningful dialog established that overcomes the sometimes arcane jargon used in each field. Access to tumor tissue has also been a problem and the role of the pathologist is critical here. Pathologists, especially the new generation of molecular pathologists, can also provide the pivotal link between basic and clinical research. Finally, applied translational research has frequently been seen as inferior to 'pure' basic research. With the application of cutting edge technology and fundamental biological principles to translational research, it's clear that addressing clinical realities is as pure a science as any.

Increasingly, biology needs to have a strong role in the design and analysis of clinical trials. It is generally accepted that targeted cancer drugs cannot be used on a 'one size fits all' model and trials need to reflect the original fundamental biology. This means designing trials with solid pre-clinical laboratory work and where the patient subgroup to be treated is refined according to precise biomarkers, such as specific oncogene mutations. We argue elsewhere (AA and JS DeBono, unpublished work) that biomarkers for drug efficacy and patient selection need to be developed and integrated very early in the clinical trials process, such as in phase 1. Again, this means that biologists need to work closely with clinicians as drugs are developed, which in the past has been highly unusual. Likewise, studying cancers in the neo-adjuvant context (before definitive surgery) or in short 'window of opportunity' studies (where a therapy is administered and its molecular consequences closely followed using biopsies over a relatively short period of time or 'window') provides a wealth of material for the biologist to study drug responses in real tumors in situ. Finally, at least in the advanced cancer setting, resistance is at present almost inevitable, and the ability to obtain and study metastatic biopsies will be critical in understanding these mechanisms. Moreover, this will allow testing of hypotheses developed in cell line or animal models of drug resistance in the genuine clinical context [74].

Most cancer drug development is now biology driven. However, to ensure that fundamental new insights into the biology of cancer are used, it is essential that integrated approaches are used. This operates both at the level of the experimental approaches, taking full account of the complexity of cancer, but also at the level of interaction of different disciplines. Although the trend will be towards 'big' science, there is still an important role for the biologist in proving insight from hypothesisbased approaches as long as this is applied appropriately. A large number of significant challenges in cancer remain, such as the relentless plasticity of the cancer genome and the Darwinian selection of resistance that results. However, with a true concord between biologists, oncologists, pharmaceutical companies and patients we believe that what we all want can be achieved: effective treatments for cancer.

\section{Acknowledgements}

We thank members of the Gene Function laboratory and the Breakthrough Centre for helpful discussions. We also thank Julian Lewis for suggesting this review and for inspiration. Our research is funded by Breakthrough Breast Cancer, CRUK, The Breast Cancer Campaign, The Breast Cancer Research Foundation and the AACR.

Published: 12 April 2010

\section{References}

1. Strebhardt K, Ullrich A: Paul Ehrlich's magic bullet concept: 100 years of progress. Nat Rev Cancer 2008, 8:473-480.

2. Hirsch J: An anniversary for cancer chemotherapy. JAMA 2006, 296:1518-1520.

3. Goodman L: Landmark article Sept. 21, 1946: Nitrogen mustard therapy. Use of methyl-bis(beta-chloroethyl)amine hydrochloride and tris(betachloroethyl)amine hydrochloride for Hodgkin's disease, lymphosarcoma, leukemia and certain allied and miscellaneous disorders. JAMA 1984, 251:2255-2261

4. Farber S, Diamond L, Mercer R, Sylvester R, Wolff J: Temporary remissions in acute leukemia in children produced by folic antagonist, 4-aminopteroylglutamic acid (aminopterin). N Engl J Med 1948, 238:787-793.

5. Hitchings $\mathrm{G}$, Elion $\mathrm{G}$ : The chemistry and biochemistry of purine analogs. Ann NY Acad Sci 1954, 60:195-199.

6. Johnson IS, Armstrong JG, Gorman M, Burnett JP Jr: The vinca alkaloids: a new class of oncolytic agents. Cancer Res 1963, 23:1390-1427.

7. Frei E: A comparative study of two regimens of combination chemotherapy in acute leukemia. Blood 1958, 13:1126-1148.

8. Cole MP, Jones CT, Todd ID: A new anti-oestrogenic agent in late breast cancer. An early clinical appraisal of ICI46474. Br J Cancer 1971, 25:270-275.

9. Bennett J: Case of hypertrophy of the spleen and liver in which death took place from suppuration of the blood. Edinburgh Med Surgical $J 1845$, 64:413-423.

10. Geary CG: The story of chronic myeloid leukaemia. Br J Haemato/ 2000, 110:2-11.

11. Nowell $P$, Hungerford $D$ : A minute chromosome in human chronic granulocytic leukemia. Science 1960, 132:1497.

12. Rowley JD: Letter: A new consistent chromosomal abnormality in chronic myelogenous leukaemia identified by quinacrine fluorescence and Giemsa staining. Nature 1973, 243:290-293.

13. Abelson HT, Rabstein LS: Lymphosarcoma: virus-induced thymicindependent disease in mice. Cancer Res 1970, 30:2213-2222.

14. Goff SP, Gilboa E, Witte ON, Baltimore D: Structure of the Abelson murine leukemia virus genome and the homologous cellular gene: studies with cloned viral DNA. Cell 1980, 22:777-785.

15. de Klein A, van Kessel AG, Grosveld G, Bartram CR, Hagemeijer A, Bootsma D, Spurr NK, Heisterkamp N, Groffen J, Stephenson JR: A cellular oncogene is translocated to the Philadelphia chromosome in chronic myelocytic leukaemia. Nature 1982, 300:765-767.

16. Groffen J, Stephenson JR, Heisterkamp N, de Klein A, Bartram CR, Grosveld G: Philadelphia chromosomal breakpoints are clustered within a limited region, bcr, on chromosome 22 . Cell 1984, 36:93-99.

17. Shtivelman E, Lifshitz B, Gale RP, Canaani E: Fused transcript of abl and bcr genes in chronic myelogenous leukaemia. Nature 1985, 315:550-554.

18. Sefton BM, Hunter T, Raschke WC: Evidence that the Abelson virus protein functions in vivo as a protein kinase that phosphorylates tyrosine. Proc Natl Acad Sci USA 1981, 78:1552-1556.

19. Konopka JB, Watanabe SM, Witte ON: An alteration of the human c-abl protein in K562 leukemia cells unmasks associated tyrosine kinase activity. Cell 1984, 37:1035-1042. 
20. Heisterkamp N, Jenster G, ten Hoeve J, Zovich D, Pattengale PK, Groffen J: Acute leukaemia in bcr/abl transgenic mice. Nature 1990, 344:251-253.

21. Daley GQ, Van Etten RA, Baltimore D: Induction of chronic myelogenous leukemia in mice by the P210bcr/abl gene of the Philadelphia chromosome. Science 1990, 247:824-830.

22. Melo JV, Deininger MW: Biology of chronic myelogenous leukemiasignaling pathways of initiation and transformation. Hematol Oncol Clin North Am 2004, 18:545-568, vii-viii.

23. Yaish P, Gazit A, Gilon C, Levitzki A: Blocking of EGF-dependent cell proliferation by EGF receptor kinase inhibitors. Science 1988, 242:933-935.

24. Piwnica-Worms H, Williams NG, Cheng SH, Roberts TM: Regulation of pp60c-src and its interaction with polyomavirus middle T antigen in insect cells. J Virol 1990, 64:61-68.

25. Druker BJ, Tamura S, Buchdunger E, Ohno S, Segal GM, Fanning S, Zimmermann J, Lydon NB: Effects of a selective inhibitor of the Abl tyrosine kinase on the growth of Bcr-Abl positive cells. Nat Med 1996, 2:561-566.

26. Druker BJ, Talpaz M, Resta DJ, Peng B, Buchdunger E, Ford JM, Lydon NB, Kantarjian H, Capdeville R, Ohno-Jones S, Sawyers CL: Efficacy and safety of a specific inhibitor of the BCR-ABL tyrosine kinase in chronic myeloid leukemia. N Engl J Med 2001, 344:1031-1037.

27. Gorre ME, Mohammed M, Ellwood K, Hsu N, Paquette R, Rao PN, Sawyers CL: Clinical resistance to STI-571 cancer therapy caused by BCR-ABL gene mutation or amplification. Science 2001, 293:876-880.

28. Corbin AS, Buchdunger E, Pascal F, Druker BJ: Analysis of the structural basis of specificity of inhibition of the Abl kinase by STI571. J Biol Chem 2002, 277:32214-32219.

29. Schindler T, Bornmann W, Pellicena P, Miller WT, Clarkson B, Kuriyan J: Structural mechanism for STI-571 inhibition of abelson tyrosine kinase. Science 2000, 289:1938-1942.

30. Weisberg E, Manley PW, Breitenstein W, Bruggen J, Cowan-Jacob SW, Ray A, Huntly B, Fabbro D, Fendrich G, Hall-Meyers E, Kung AL, Mestan J, Daley GQ Callahan L, Catley L, Cavazza C, Azam M, Neuberg D, Wright RD, Gilliland DG, Griffin JD: Characterization of AMN107, a selective inhibitor of native and mutant Bcr-Abl. Cancer Cell 2005, 7:129-141.

31. Lombardo LJ, Lee FY, Chen P, Norris D, Barrish JC, Behnia K, Castaneda S, Cornelius LA, Das J, Doweyko AM, Fairchild C, Hunt JT, Inigo I, Johnston K, Kamath A, Kan D, Klei H, Marathe P, Pang S, Peterson R, Pitt S, Schieven GL, Schmidt RJ, Tokarski J, Wen ML, Wityak J, Borzilleri RM: Discovery of $\mathrm{N}$-(2-chloro-6-methyl- phenyl)-2-(6-(4-(2-hydroxyethyl)- piperazin-1-yl)-2methylpyrimidin-4-ylamino)thiazole-5-carboxamide (BMS-354825), a dual $\mathrm{Src} / \mathrm{Abl}$ kinase inhibitor with potent antitumor activity in preclinical assays. J Med Chem 2004 47:6658-6661.

32. Zhang J, Adrian FJ, Jahnke W, Cowan-Jacob SW, Li AG, lacob RE, Sim T, Powers J, Dierks C, Sun F, Guo GR, Ding Q, Okram B, Choi Y, Wojciechowski A, Deng X, Liu G, Fendrich G, Strauss A, Vajpai N, Grzesiek S, Tuntland T, Liu Y, Bursulaya B, Azam M, Manley PW, Engen JR, Daley GQ, Warmuth M, Gray NS: Targeting Bcr-Abl by combining allosteric with ATP-binding-site inhibitors. Nature 2010, 463:501-506

33. Siddiqui MA, Scott LJ: Imatinib: a review of its use in the management of gastrointestinal stromal tumours. Drugs 2007, 67:805-820.

34. Apperley JF, Gardembas M, Melo JV, Russell-Jones R, Bain BJ, Baxter EJ, Chase A, Chessells JM, Colombat M, Dearden CE, Dimitrijevic S, Mahon FX, Marin D, Nikolova Z, Olavarria E, Silberman S, Schultheis B, Cross NC, Goldman JM: Response to imatinib mesylate in patients with chronic myeloproliferative diseases with rearrangements of the platelet-derived growth factor receptor beta. N Engl J Med 2002, 347:481-487.

35. Zhang J, Yang PL, Gray NS: Targeting cancer with small molecule kinase inhibitors. Nat Rev Cancer 2009, 9:28-39.

36. Baselga J, Swain SM: Novel anticancer targets: revisiting ERBB2 and discovering ERBB3. Nat Rev Cancer 2009, 9:463-475.

37. Von Hoff DD, LoRusso PM, Rudin CM, Reddy JC, Yauch RL, Tibes R, Weiss GJ, Borad MJ, Hann CL, Brahmer JR, Mackey HM, Lum BL, Darbonne WC, Marsters JC Jr, de Sauvage FJ, Low JA: Inhibition of the hedgehog pathway in advanced basal-cell carcinoma. N Engl J Med 2009, 361:1164-1172.

38. Rudin CM, Hann CL, Laterra J, Yauch RL, Callahan CA, Fu L, Holcomb T, Stinson J, Gould SE, Coleman B, LoRusso PM, Von Hoff DD, de Sauvage FJ, Low JA: Treatment of medulloblastoma with hedgehog pathway inhibitor GDC-0449. N Engl J Med 2009, 361:1173-1178.

39. Nusslein-Volhard C, Wieschaus E: Mutations affecting segment number and polarity in Drosophila. Nature 1980, 287:795-801

40. Jiang J, Hui CC: Hedgehog signaling in development and cancer. Dev Cell
2008, 15:801-812.

41. Gray-Schopfer V, Wellbrock C, Marais R: Melanoma biology and new targeted therapy. Nature 2007, 445:851-857.

42. Dhomen N, Marais R: BRAF signaling and targeted therapies in melanoma. Hematol Oncol Clin North Am 2009, 23:529-545, ix.

43. Chapman P, Puzano V, Sosman J, Kim K, Ribas A, McArthur G, Lee R, Grippo J, Nolop K, Flaherty KR: Early efficacy signal demonstrated in advanced melanoma in a phase I trial of the oncogenic BRAF-selective inhibitor PLX4032. Eur J Cancer Supp/ 2009, 7:5.

44. Heidorn SJ, Milagre C, Whittaker, S., Nourry A, Niculescu-Duvas I, Dhomen N, Hussain J, Reis Filho JS, Springer CS, Pritchard C, Marais R: Kinase-dead BREF and oncogenic RAS cooperate to drive tumor progression through CRAF. Cell 2010, 140:209-21.

45. Hanahan D, Weinberg RA: The hallmarks of cancer. Cell 2000, 100:57-70.

46. Luo J, Solimini NL, Elledge SJ: Principles of cancer therapy: oncogene and non-oncogene addiction. Cell 2009, 136:823-837.

47. Kroemer G, Pouyssegur J: Tumor cell metabolism: cancer's Achilles' heel. Cancer Cell 2008, 13:472-482.

48. Hoeijmakers JH: DNA damage, aging, and cancer. N Engl J Med 2009, 361:1475-1485.

49. Morimoto RI: Proteotoxic stress and inducible chaperone networks in neurodegenerative disease and aging. Genes Dev 2008, 22:1427-1438.

50. Holland AJ, Cleveland DW: Boveri revisited: chromosomal instability, aneuploidy and tumorigenesis. Nat Rev Mol Cell Biol 2009, 10:478-487.

51. Warburg O: On the origin of cancer cells. Science 1956, 123:309-314.

52. Benz CC, Yau C: Ageing, oxidative stress and cancer: paradigms in parallax. Nat Rev Cancer 2008, 8:875-879.

53. Christofk HR, Vander Heiden MG, Harris MH, Ramanathan A, Gerszten RE, Wei R, Fleming MD, Schreiber SL, Cantley LC: The M2 splice isoform of pyruvate kinase is important for cancer metabolism and tumour growth. Nature 2008, 452:230-233.

54. Farmer H, McCabe N, Lord CJ, Tutt AN, Johnson DA, Richardson TB, Santarosa M, Dillon KJ, Hickson I, Knights C, Martin NM, Jackson SP, Smith GC, Ashworth A: Targeting the DNA repair defect in BRCA mutant cells as a therapeutic strategy. Nature 2005, 434:917-921.

55. Kaelin WG Jr: The concept of synthetic lethality in the context of anticancer therapy. Nat Rev Cancer 2005, 5:689-698.

56. Fong PC, Boss DS, Yap TA, Tutt A, Wu P, Mergui-Roelvink M, Mortimer P, Swaisland H, Lau A, O'Connor MJ, Ashworth A, Carmichael J, Kaye SB, Schellens JH, de Bono JS: Inhibition of poly(ADP-ribose) polymerase in tumors from BRCA mutation carriers. N Engl J Med 2009, 361:123-134

57. Weinstein IB, Begemann M, Zhou P, Han EK, Sgambato A, Doki Y, Arber N, Ciaparrone $\mathrm{M}$, Yamamoto $\mathrm{H}$ : Disorders in cell circuitry associated with multistage carcinogenesis: exploitable targets for cancer prevention and therapy. Clin Cancer Res 1997, 3:2696-2702.

58. Iorns E, Lord CJ, Turner N, Ashworth A: Utilizing RNA interference to enhance cancer drug discovery. Nat Rev Drug Discov 2007, 6:556-568

59. Scholl C, Frohling S, Dunn IF, Schinzel AC, Barbie DA, Kim SY, Silver SJ, Tamayo P, Wadlow RC, Ramaswamy S, Döhner K, Bullinger L, Sandy P, Boehm JS, Root DE, Jacks T, Hahn WC, Gilliland DG: Synthetic lethal interaction between oncogenic KRAS dependency and STK33 suppression in human cancer cells. Cell 2009, 137:821-834.

60. Luo J, Emanuele MJ, Li D, Creighton CJ, Schlabach MR, Westbrook TF, Wong KK, Elledge SJ: A genome-wide RNAi screen identifies multiple synthetic lethal interactions with the Ras oncogene. Cell 2009, 137:835-848.

61. Barbie DA, Tamayo P, Boehm JS, Kim SY, Moody SE, Dunn IF, Schinzel AC, Sandy P, Meylan E, Scholl C Fröhling S, Chan EM, Sos ML, Michel K, Mermel C, Silver SJ, Weir BA, Reiling JH, Sheng Q, Gupta PB, Wadlow RC, Le H, Hoersch S, Wittner BS, Ramaswamy S, Livingston DM, Sabatini DM, Meyerson M, Thomas RK, Lander ES, et al:: Systematic RNA interference reveals that oncogenic KRAS-driven cancers require TBK1. Nature 2009, 462:108-112.

62. Wang Y, Engels IH, Knee DA, Nasoff M, Deveraux QL, Quon KC: Synthetic lethal targeting of MYC by activation of the DR5 death receptor pathway. Cancer Cell 2004, 5:501-512.

63. Firestein R, Bass AJ, Kim SY, Dunn IF, Silver SJ, Guney I, Freed E, Ligon AH, Vena N, Ogino S, Chheda MG, Tamayo P, Finn S, Shrestha Y, Boehm JS, Jain S, Bojarski E, Mermel C, Barretina J, Chan JA, Baselga J, Tabernero J, Root DE, Fuchs CS, Loda M, Shivdasani RA, Meyerson M, Hahn WC: CDK8 is a colorectal cancer oncogene that regulates beta-catenin activity. Nature 2008, 455:547-551.

64. Boehm JS, Zhao JJ, Yao J, Kim SY, Firestein R, Dunn IF, Sjostrom SK, Garraway 
LA, Weremowicz S, Richardson AL, Greulich H, Stewart CJ, Mulvey LA, Shen RR, Ambrogio L, Hirozane-Kishikawa T, Hill DE, Vidal M, Meyerson M, Grenier JK, Hinkle G, Root DE, Roberts TM, Lander ES, Polyak K, Hahn WC: Integrative genomic approaches identify IKBKE as a breast cancer oncogene. Cell 2007, 129:1065-1079.

65. Hahn CK, Berchuck JE, Ross KN, Kakoza RM, Clauser K, Schinzel AC, Ross L, Galinsky I, Davis TN, Silver SJ , Root DE, Stone RM, DeAngelo DJ, Carroll M, Hahn WC, Carr SA, Golub TR, Kung AL, Stegmaier K: Proteomic and genetic approaches identify Syk as an AML target. Cancer Cell 2009, 16:281-294.

66. Campbell PJ, Stephens PJ, Pleasance ED, O'Meara S, Li H, Santarius T, Stebbings LA, Leroy C, Edkins S, Hardy C, Teague JW, Menzies A, Goodhead I, Turner DJ, Clee CM, Quail MA, Cox A, Brown C, Durbin R, Hurles ME, Edwards $P A$, Bignell GR, Stratton MR, Futreal PA: Identification of somatically acquired rearrangements in cancer using genome-wide massively parallel pairedend sequencing. Nat Genet 2008, 40:722-729.

67. Shah SP, Morin RD, Khattra J, Prentice L, Pugh T, Burleigh A, Delaney A, Gelmon K, Guliany R, Senz J, Steidl C, Holt RA, Jones S, Sun M, Leung G, Moore R, Severson T, Taylor GA, Teschendorff AE, Tse K, Turashvili G, Varhol R, Warren RL, Watson P, Zhao Y, Caldas C, Huntsman D, Hirst M, Marra MA, Aparicio S: Mutational evolution in a lobular breast tumour profiled at single nucleotide resolution. Nature 2009, 461:809-813

68. Pleasance ED, Stephens PJ, O'Meara S, McBride DJ, Meynert A, Jones D, Lin ML, Beare D, Lau KW, Greenman C, Varela I, Nik-Zainal S, Davies HR, Ordoñez GR, Mudie LJ, Latimer C, Edkins S, Stebbings L, Chen L, Jia M, Leroy C, Marshall J, Menzies A, Butler A, Teague JW, Mangion J, Sun YA, McLaughlin SF, Peckham HE, Tsung EF: A small-cell lung cancer genome with complex signatures of tobacco exposure. Nature 2010, 463:184-190.

69. Pleasance ED, Cheetham RK, Stephens PJ, McBride DJ, Humphray SJ, Greenman CD, Varela I, Lin ML, Ordóñez GR, Bignell GR, Ye K, Alipaz J, Bauer MJ, Beare D, Butler A, Carter RJ, Chen L, Cox AJ, Edkins S, Kokko-Gonzales PI, Gormley NA, Grocock RJ, Haudenschild CD, Hims MM, James T, Jia M,
Kingsbury Z, Leroy C, Marshall J, Menzies A, et al:: A comprehensive catalogue of somatic mutations from a human cancer genome. Nature 2010, 463:191-196

70. Stephens PJ, McBride DJ, Lin ML, Varela I, Pleasance ED, Simpson JT, Stebbings LA, Leroy C, Edkins S, Mudie LJ, Greenman CD, Jia M, Latimer C, Teague JW, Lau KW, Burton J, Quail MA, Swerdlow H, Churcher C, Natrajan R, Sieuwerts AM, Martens JW, Silver DP, Langerød A, Russnes HE, Foekens JA, Reis-Filho JS, van't Veer L, Richardson AL, Børresen-Dale AL, Campbell PJ, Futreal PA, Stratton MR: Complex landscapes of somatic rearrangement in human breast cancer genomes. Nature 2009, 462:1005-1010.

71. Perou CM, Sorlie T, Eisen MB, van de Rijn M, Jeffrey SS, Rees CA, Pollack JR, Ross DT, Johnsen H, Akslen LA, Fluge O, Pergamenschikov A, Williams C, Zhu SX, Lønning PE, Børresen-Dale AL, Brown PO, Botstein D: Molecular portraits of human breast tumours. Nature 2000, 406:747-752

72. Griffin NM, Yu J, Long F, Oh P, Shore S, Li Y, Koziol JA, Schnitzer JE: Label-free, normalized quantification of complex mass spectrometry data for proteomic analysis. Nat Biotechnol 2010, 28:83-89.

73. Nicholson JK, Connelly J, Lindon JC, Holmes E: Metabonomics: a platform for studying drug toxicity and gene function. Nat Rev Drug Discov 2002, 1:153-161.

74. Edwards SL, Brough R, Lord CJ, Natrajan R, Vatcheva R, Levine DA, Boyd J, Reis-Filho JS, Ashworth A: Resistance to therapy caused by intragenic deletion in BRCA2. Nature 2008, 451:1111-1115.

75. Deininger MW, Goldman JM, Melo JV: The molecular biology of chronic myeloid leukemia. Blood 2000, 96:3343-3356.

76. Druker BJ: Translation of the Philadelphia chromosome into therapy for CML. Blood 2008, 112:4808-4817.

doi:10.1186/1741-7007-8-38

Cite this article as: Lord CJ, Ashworth A: Biology-driven cancer drug

development: back to the future. BMC Biology 2010, 8:38. 